OLIVER H TURNBULL Department of Psychology, King's College,
Aberdeen University, Aberdeen $A B 92 U B$, Scotland

Correspondence to: Dr O Turnbull.

1 Bisiach E, Vallar G. Hemineglect in humans. In: Boller F, Grafman J, eds. Handbook of neuropsychology. Vol 1. Amsterdam: Elsevier, neuropsyc.

2 Critchley M. Misoplegia, or hatred of hemiplegia. Mt Sinai f Med 1974;41:82-7.

3 Fredericks JAM. Disorders of the body schema. In: Vinken PJ, Bruyn GW, Klawans HL, Fredericks JAM, eds. Handbook of clinical neurology. Amsterdam: Elsevier, 1985.

4 Ferro JF, Martins IP, Tavoro L. Neglect in children. Ann Neurol 1984;15:281-4.

5 Thompson NM, Ewing-Cobbs L, Fletcher JM, Miner ME, Levin HS. Left unilateral neglect in a preschool child. Dev Med Child Neurol 1991;33:636-44.

\section{Valproate induced encephalopathy} treated with carnitine in an adult

Hepatotoxicity due to valproate often necessitates discontinuation of the drug. We report a patient with unstable epilepsy in whom valproate was an irreplaceable component of anticonvulsant treatment. Hepatic encephalopathy was reversed and remained controlled by combining carnitine supplementation with an essentially unchanged valproate schedule.

A 35 year old previously healthy woman developed status epilepticus secondary to viral encephalitis initially requiring mechanical ventilation and phenobarbitone concentrations of over $100 \mathrm{mg} / 1$ with phenytoin to maintain seizure control. Phenytoin was discontinued due to rash and replaced by carbamazepine, which was subsequently withdrawn due to abnormal liver function tests and sedation. Valproate was initiated in combination with phenobarbitone. Isolated generalised breakthrough seizures sometimes associated with urinary tract infections continued during a period of rehabilitation.

Thirteen months after her initial illness, she was again admitted after three days of increasing confusion, drowsiness, and tremulousness without seizure activity. On examination, delirium with asterixis raised the clinical suspicion of hepatic encephalopathy. Routine blood tests including white blood count and liver function tests were normal, and anticonvulsant concentrations were therapeutic (phenobarbitone $34.2 \mathrm{mg} / \mathrm{l}$, valproate $83 \mathrm{mg} / \mathrm{l}$ ). Serum ammonia on admission was $43 \mu \mathrm{mol} / 1$ (nor$\mathrm{mal}<33 \mu \mathrm{mol} / \mathrm{l}$ ), rising to $215 \mu \mathrm{mol} / 1$ by the next morning. Serum free carnitine was $7.6 \mu \mathrm{mol} / 1$ (normal $19.0-60.0 \mu \mathrm{mol} / \mathrm{l}$ ) and total carnitine $15.4 \mu \mathrm{mol} / 1$ (normal 30.0-73.0 $\mu \mathrm{mol} / \mathrm{l}$ ). Phenobarbitone was maintained and valproate decreased from $3 \mathrm{~g}$ to $2.75 \mathrm{~g}$ a day with supplemental L-carnitine added ( $330 \mathrm{mg}$ four times daily). The delirium and asterixis resolved over the next three days permitting discharge on the fourth hospital day with normal serum ammonia $(25 \mu \mathrm{mol} / \mathrm{l})$ and therapeutic valproate concentrations $(93 \mathrm{mg} / \mathrm{l})$.

Valproate has been shown to cause reduced serum carnitine concentrations and hyperammonaemia in certain children when compared with the administration of other antiepileptic drugs. ${ }^{1}$ However, not all valproate induced hepatotoxicity is carnitine related. Children at greatest risk are those receiving a multidrug anticonvulsant regimen. The condition usually develops within a few months of starting valproate.

Carnitine supplementation has been used to prevent hepatotoxicity in children considered at increased risk due to suspected mitochondrial disorder, malnutrition, mental retardation, high dose valproate treatment, or a history of hepatotoxicity to the valproate. ${ }^{2}$ Treatment with oral carnitine has also been reported to reverse this hepatotoxicity in children despite continued valproate.

Less is known about the relation between valproate induced hepatotoxicity and carnitine deficiency in adults. Reduced free carnitine concentrations have been reported in $76.5 \%$ of adults receiving anticonvulsant drug regimens including valproate compared with $21.5 \%$ of adults on schedules without valproate. ${ }^{4}$ Coma from valproate induced carnitine deficiency in adults is reported to respond rapidly to discontinuation of the drug. 5

This case shows that certain adults receiving valproate are, like children, at risk for carnitine deficiency and hyperammonaemia with its clinical accompaniment. The incidence among encephalopathic adults on valproate is unknown. This patient further illustrates that identification and correction of a drug induced deficiency may allow continuation of treatment without disturbing control of an unstable seizure disorder. Much as folate is used in chronic phenytoin administration, supplemental carnitine should be considered in adult patients with epilepsy at risk for hyperammonaemia.

DAVID BEVERSDORF COLIN ALLEN Section of Neurology, Department of Medicine RICHARD NORDGREN Department of Pediatrics, Dartmouth-Hitchcock Medical Center, 1 Medical Center Drive, Lebanon NH 03756, USA

Correspondence to: Dr D Beversdorf, Department of Neurology, University of Florida College of Medicine, SW 1600 Archer Road, Gainesville, FL 32610, USA.

1 Thom H, Carter PE, Cole GF, Stevenson KL. Ammonia and carnitine concentrations in children treated with sodium valproate comchildren treated with sodium valproate compared Whild Neurol 1991;33:795-802.

2 Sugimoto T, Nishida N, Murakami K, et al. Valproate-induced hepatotoxicity: protective effect of L-carnitine supplementation. $\mathcal{F p n} \mathcal{F}$ Psychiatry Neurol (Tokyo) 1990;44:387-8.

3 Vance CK, Vance WH, Winter SC, Opala G, Szabo A. Control of valproate-induced hepatotoxicity with carnitine. Ann Neurol 1989; 26:456.

4 Rodriguez-Segade S, Alonso de la Peña C, Tutor JC, et al. Carnitine deficiency associated with anticonvulsant therapy. Clin Chim Acta 1989;181:175-82.

5 Triggs WT, Bohan TP, Lin S-N, Willmore LJ. Valproate-induced coma with ketosis and carnitine deficiency. Arch Neurol 1990;47: carnitine

Increased serum neopterin concentrations in a patient with Creutzfeldt-Jakob disease

Spongiform encephalopathies or prion diseases affect both human beings and animals. The human transmissible spongiform encephalopathies include Kuru, CreutzfeldtJakob disease, and the GerstmannSträussler-Scheinker syndrome (GSS), and fatal familial insomnia; all these diseases are associated with the accumulation of $\beta$ pleated amyloid protein in the brain.
Besides genetic abnormalities, epidemiological studies disclosed that a transmissible agent is involved in the spread of Creutzfeldt-Jakob disease, ${ }^{1}$ and small viruslike structures in brains from sporadic and familial Creutzfeldt-Jakob disease and GSS have been described. ${ }^{2}$ More recently the possible association between bovine spongiform encephalopathies and CreutzfeldtJakob disease received much attention.

In a study comprising patients with neurodegenerative disorders we had the opportunity to examine a 67 year old woman who was clinically suspected of having Creutzfeldt-Jakob disease. She had shown rapidly progressive dementia, typical EEG patterns, and myoclonus; intercurrent illness was apparent. The woman died five months after the onset of clinical symptoms. At necropsy, performed by one of us ( $\mathrm{KJ})$, diffuse spongiform changes were found in the cerebral cortex, thalamus, striatum, and cerebellum associated with neuronal loss and astroglial proliferation, confirming the diagnosis of Creutzfeldt-Jakob disease. Blood specimens were obtained two months and one month before death. Among other routine laboratory tests, neopterin concentrations were measured by enzyme linked immunosorbent assay (ELISA; BRAHMSDiagnostica, Berlin, Germany). Neopterin concentrations were $16.3 \mathrm{nmol} / 1$ (first occasion) and $12.4 \mathrm{nmol} / 1$ (second occasion), clearly raised compared with the serum neopterin concentrations in healthy controls (mean (SD) $5.4(2 \cdot 3) \mathrm{nmol} / \mathrm{l})$.

Increased neopterin concentrations are indicative of activation of cell mediated immunity in humans, because large amounts of neopterin are released from human monocytes and macrophages on stimulation with interferon- $\gamma^{4}$ Similarly, increased neopterin concentrations are often found in body fluids of patients with infections, autoimmune disorders, or certain types of malignancies, usually correlating with the extent and the activity of the diseases and giving prognostic information. ${ }^{34}$ Also in various infections of the CNS increased neopterin concentrations, preferentially in the CSF, have been reported. ${ }^{5}$ Thus increased serum neopterin is by no means specific for Creutzfeldt-Jakob disease but provides a hint that the cell mediated immune system was chronically activated in our patient with late stage Creutzfeldt-Jakob disease. This is surprising as there is no evidence so far that prion diseases are associated with abnormal cellular immunity. We are unable to deduce at which stage of disease immune deterioration may start in Creutzfeldt-Jakob disease, when an increase of serum neopterin may begin, and whether the presence of any transmissible agent was the cause of increased neopterin in the patient. Further studies involving larger numbers of patients are required to answer these questions.

F LEBLHUBER
J WALLI
Department of Gerontology,
Linz, Austria
G P TILZ
Landesnervenklinik Wagner-faurgg,
Department of Internal Medicine,
University of Graz, Graz, Austria
K JELINGER
Department of Neurology and
Ludwig Boltzmann Institute of Neurobiology,
Lainz-Hospital, Vienna, Austria
H WACHTER
D FUCHS
Institute of Medical Chemistry and Biochemistry and
Ludwig Boltzmann Institute of AIDS-Research,
University of Innsbruck,
Innsbruck, Austria


Correspondence to: Dr D Fuchs, Institute of Medical Chemistry and Biochemistry, University of Innsbruck, Fritz Pregl Strasse 3, A-6020 Innsbruck, Austria.

1 Goldfarb LG, Brown P. The transmissible spongiform encephalopathies. Ann Rev Med 1995;46:57-65.

2 Ozel M, Xi YG, Baldauf E, Diringer $H$,
Pocchiari M. Small virus-like structure in brains from cases of sporadic and familial Creutzfeldt-Jakob disease. Lancet 1994;344: 923-4

3 Fuchs D, Weiss G, Reibnegger G, Wachter H. The role of neopterin as a monitor of cellula immune activation in transplantation, inflammatory, infectious and malionant diseases. Crit Rev Clin Lab Sci 1992;29:304-41.
4 Fuchs D, Weiss G, Wachter H. Neopterin, biochemistry and clinical use as a marker for cellular immune reactions. Int Arch Allergy Immunol 1993;101:1-6.

5 Hagberg L, Dotevall L, Norkrans G, Larsson $M$, Wachter H, Fuchs D. Cerebrospinal fluid neopterin concentrations in central nervous system infection. F Infect Dis 1993;168: 1285-8. 